\title{
Contents and Ways of Organizational-Financial Risks Reduction among Managing Subjects in Housing and Utility Service
}

\author{
Margarita D. Miroonova $^{1}$, Svetlana V. Markova ${ }^{2}$, Zulfira N. Zapparova ${ }^{3}$, Ekaterina A. Kameneva ${ }^{4}$ \\ 1, 2, ${ }^{3}$ Kazan Federal University, ${ }^{4}$ Financial University under the Government of the Russian Federation \\ Eamil: marg.mironova2011@yandex.ru, kameneva.e@ rambler.ru, zulfira.zapparova@gmail.com
}

Received: 21st October 2017 Accepted: 16th November 2017, Published: 31st December 2017

\begin{abstract}
This work identified, summarized and systematized the organizational and financial risks inherent in managing entities within the housing and communal services in the modern conditions of Russian economy. In order to carry out the research, the authors of the article used the methods of structural, comparative and statistical analysis. The study revealed the content of organizational and financial risks that affect the financial performance of managing subjects of the housing and communal services. Using the example of the cost management model to minimize the risks of managing subject within the housing and communal services, an effective cost value was calculated. The study showed that the value of the cost-effectiveness ratio is sharply reduced with the increase of cost volume to minimize the consequences of industrial and technological risks. At that, the choice of the optimal value for the cost-effectiveness factor, provided that production and technological risks are minimized, will be realized in conjunction with the level of losses acceptable to the enterprise due to the implementation of the risk event. The work also examined the content and the factors of specific risks for the housing and communal services sector, such as the risk of non-payment for the population, the risk of budgetary defaults and the risk of bankruptcy. The materials of the article are of practical value for the management of housing and communal enterprises interested in reduction or complete avoidance of industry specific risks and the increase of economic entity financial stability.
\end{abstract}

Keywords: Organizational and Financial Risks, Housing and Communal Services, Managing Entity, Financing

\section{Introduction}

Housing and communal services as the most important branch of the economy ensures the continuous production of housing and communal services, forms quality indicators of the human life support environment. The effectiveness of economic transformations in the housing and communal sector is largely determined by the strategic focus of the management system, which allows the utility enterprises to adapt to changing market conditions. The problem of risk, considered at first as a hidden effect, is perceived currently as a basic component of economic entity management mechanisms at all levels of the economy.

According to the sociologist U. Beck [1], the features of risks are demonstrated in society which is not able to react quickly to the emerging risk situation and, as a consequence, either intensifies the risk factors or generates new ones. At present, understanding has come concerning the need to develop rational approaches to risk phenomenon [2.3]. In this regard, the practice of management develops and applies various risk minimization methods that are aimed at damage reduction from the consequences of risk implementation in the form of adverse events or the avoiding of the latter [4-7]. New approaches to the management by an organization are developed based on risk prevention. In particular, such concept as "circumspection" is introduced into the strategic management of an organization [8].

As an important direction of the study concerning the essence of risks in the housing and communal sector, one can single out the studies in which risks are considered as the events that destroy a managed system $[9,10]$. This approach originates from the theoretical foundations of historical and technological development. During the development of the latter, the main focus was on the study of destructive risk patterns and characteristics [6].

\section{Materials and Methods}

The initial material was the data on the results of the 11th management company of housing and communal services of Kazan in the Republic of Tatarstan during 2013-2015. Data processing was conducted on the basis of the Department of Corporate Finance at the Finance University under the Government of Russian Federation and the Department Financial Management of the Kazan Federal University. In order to conduct research, the authors used the methods of structural, comparative and statistical analysis of organizational and financial risks that have a significant impact on the financial performance of managing subjects of the housing and communal services. 


\section{Results and Discussion}

The financial performance of the managing subjects is affected by a combination of organizational and financial risks. In this group of risks, the category of specific risks inherent in the housing and communal services sector is highlighted:

- Production and technological risks;

- The risks of non-payment by the population;

- The risk of fiscal non-payments;

- The risk of bankruptcy [10].

Let's consider the content of this group of risks and identify the possibility of their minimization or avoidance.

Industrial and technological risks.

The onset of unfavorable events entails the probability of an expected profit decrease due to the decrease of revenue and the increase of costs. In our study, a quantitative model to assess material damage (M) is presented, taking into account the effective costs (d) to minimize / eliminate the risk of a managing entity within the housing and communal sphere (Table 1). At the same time, the cost effectiveness for carrying out the measures to minimize possible damage is reflected in the value of the cost-effectiveness ratio $(\mathrm{K})$, calculated by the following formula:

$$
K=\frac{M_{\text {мax }}-M}{\mathrm{~d}}
$$

(1),

where $\mathrm{d}$ is the cost of undertaking the measures to reduce the amount of probable damage from the implementation of production and technological risks.

M - the magnitude of the likely damage after the carrying out of activities that minimize losses from the implementation of industrial and technological risks in the housing and communal services;

$\mathbf{M}_{\max }$ - the magnitude of the maximum damage in the implementation of industrial and technological risks, millions of rubles.

Using the example of the cost management model to minimize the risks of the managing subject of the housing and communal services, we examined the effect of effective costs on the amount of damage caused by production and technical risks (Fig. 1.2).

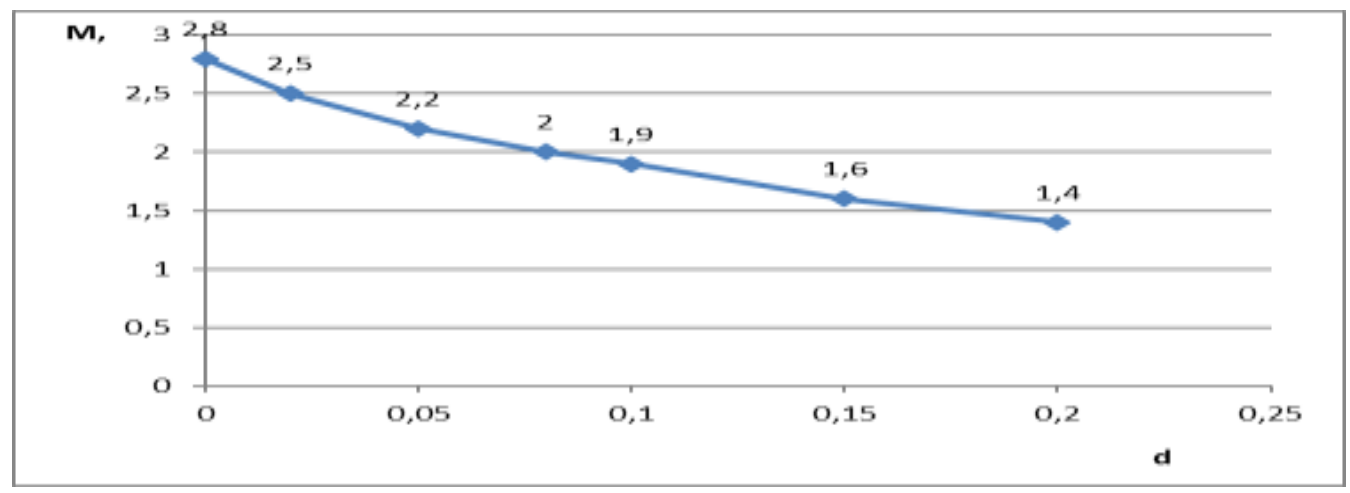

Fig. 1. Effect of Effective Costs on the Amount of Damage Caused by Industrial and Technical Risks in the Housing and Communal Services Sector, Million Rubles.

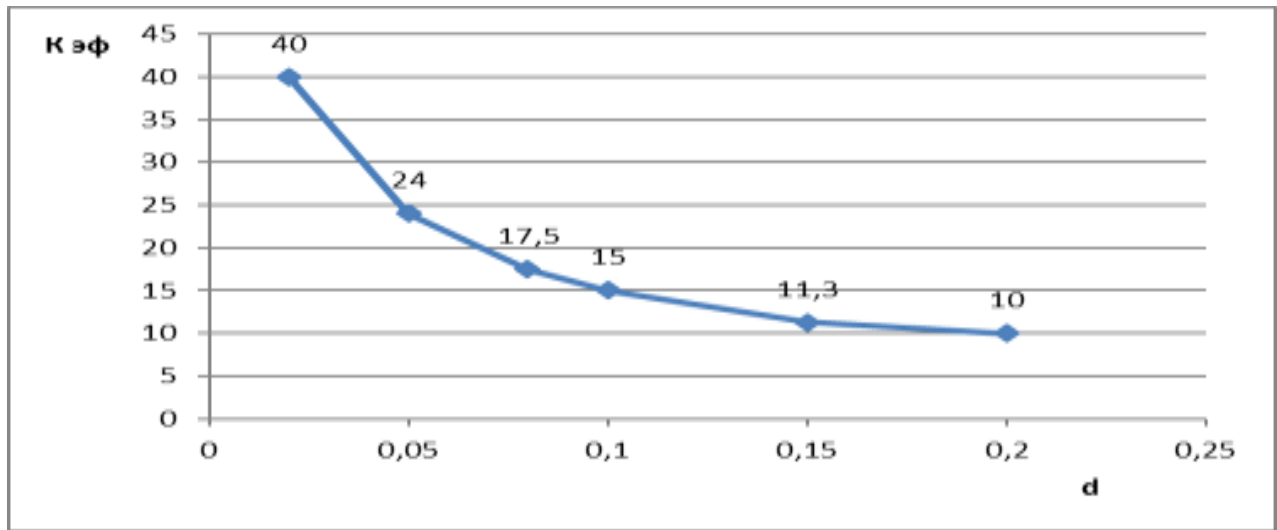

Fig. 2. The Effect of Effective Costs (Million Rubles) on the Value of the Efficiency Factor in the Housing and Communal Services Sector 
The coefficient $K_{\text {eff }}$ shows the amount of probable damage reduction per each ruble of costs to minimize production and technological risks. As our study shows, the value of the cost-effectiveness ratio is sharply reduced with the increase of costs to minimize the consequences of industrial and technological risks. But the choice of the optimal value of $\mathrm{K}_{\mathrm{eff}}$ with the minimization of production and technological risks should be inseparable from the determination of the level of losses acceptable for an enterprise due to the realization of a risk event. The justification of effective cost value choice under these restrictions will determine the strategy of production and technological risk control concerning the managing subjects of the housing and communal services.

Risk of population non-payment.

Currently, about $20 \%$ of residential premises remain state property (state, municipal housing fund), and a significant part (up to 80\%) of apartments are privately owned. This is an average indicator in Russia. Nevertheless, there is a significant differentiation concerning the houses. Russia has multi-apartment buildings, where more than $50 \%$ of the premises are in municipal ownership, others premises are private ones.

The beginning of activities for an apartment building managing can be considered the preparation and the successful holding of a general meeting of owners. The meeting of owners of premises in an apartment building is the governing body of this house.

The disunity of residents and the disbelief in a positive result can be a serious obstacle in the work of an apartment building management.

In practice, each owner (an employer) requires an individual approach, and many of them refuse to sign documents for some reason. Thus, the process of "negotiations" can last for months. However, a managing entity, from the moment of the first management agreement conclusion, assumes obligations to counterparties (resource-supplying organizations) for the payment of supply of communal resources. Therefore, indebtedness arises inevitably.

In this situation, the following steps are advisable.

First of all, it is important to conclude an agreement with each owner, since the question arises about the identity of such contract terms. One apartment building has one contract.

Secondly, since a contract can be concluded in any form envisaged for the execution of transactions, an alternative is proposed - the conclusion of a public offer. The acceptance is the payment of housing and communal services by an owner of premises in a given house within the established term.
Currently, the collection of payments for housing and communal services is $85-95 \%$ of the value of charges on the average for Russia. Thus, the managing entity has monthly receivables from nonpaying tenants, as well as the accounts payable to counterparties (resource-supplying and contracting organizations).

As for the collection of money from non-payers, in our opinion, it is expedient to solve the problem of debts with the help of collection agencies. Russian practice shows that the cooperation with collection agencies makes it possible to minimize the damage and financial risks associated with chronic nonpayment by tenants significantly.

Risk of budgetary non-payment.

The factors of this risk are the following ones:

- the absence of a contact between a managing subject and a local administration;

- Minimum transparency for the development of tariffs on utilities;

- Unsatisfactory condition of the housing fund transferred to management;

- the failure to fulfill obligations on timeliness and completeness of budgetary financing.

The analysis of the payables and receivables structure of managing entities shows that the main reason for its occurrence is the lack of full budget assignments financed from the budgets of all levels, which can lead ultimately to the bankruptcy of a managing entity.

The success of the reforms in the sphere of housing and communal services depends on the creation of favorable conditions by a local administration for the development of competition in the sphere of housing management. But often local governments hinder the activities of private structures in the management and the maintenance of housing, they create the barriers of entry into this market for commercial firms and reject private initiatives using administrative and political resources.

Also, at present, local self-government bodies are considered as an authority and as the owner of a municipal housing fund. The bodies have the right to provide financial assistance for capital repairs in the framework of targeted programs.

The cost of work on the overhaul is determined on the basis of the estimate documentation. Estimate documentation is compiled by appraisers. A client approves the works on capital repair - a managing subject. This circumstance predetermines not only the responsibility of a manager for the validity of the results indicated in an estimate, but also the availability of pricing knowledge, the standardization and the development rules and the approval of the estimation documentation.

During construction works, both savings and additional expenditures can occur. 
The most significant reasons for an inefficient use of funds during capital repairs are:

1) Low qualification of the workforce;

2) The non-compliance of repair work technology by a contractor organization in the course of residential building major repairs;

3) Incorrect decisions taken during the preparation of design estimates;

4) Obsolete equipment;

5) The ignorance of standards for repair work;

6) The violation of the technological regime during repair works [10].

The efficiency of capital repairs depends to a large extent on the implementation of this process management. A considerable attention should be paid to the following aspects:

- the control over the quality of work;

- the objectivity of information;

- the transparency of decisions;

- the rational distribution of powers.

The solution of organizational and managerial tasks during capital repairs is of great importance to improve the quality of population life and requires the increase of policy decision efficiency at the state and municipal levels.

Risk of bankruptcy. This is the most obvious financial risk of a managing entity in the current conditions of the housing and communal services operation. A managing organization without significant reserve funds, cannot cope with an emergency situation that arose at a site.

At present, due to the requirements of the legislation, the managing entities purchase the communal resources from the communal complex organizations and are obliged to pay for these resources fully and timely, regardless of consumer payment history. The structure of payments for customer servicing by a management company consists of a fee for utilities (70-80\%) and housing services (fees for maintenance and repair - 20-30\%). According to the structure of payments it is clear that a managing entity basically acts as an intermediary between a resource-supplying organization and consumers, accumulating corresponding payments and transferring them to the accounts of resource-supplying organizations. A management company can earn only by the provision of services and works on the maintenance and the repair of the common property of owners in an apartment building. This specificity negatively affects the financial condition of the managing entities, which is characterized by significant amounts of receivables from the budget and tenants, as well as by automatically arising accounts payable to the providers of communal resources. A practical solution to this problem may be the implementation of energy service investment projects [11, 12].
When in absolute terms the cost of utilities decreases with the energy consumption increase among a final consumer, a manager of a subject, besides the raising of financial stability, will have the opportunity to change the structure of payment: to increase the share of payment for maintenance and repair.

The considered organizational and financial risks show that, despite the long reforming of the housing and communal services, one of the main tasks is the replacement of administrative levers of management by the housing and communal services with economic levers - was extremely unsatisfactory. Neither the municipal authorities, nor the owners of housing, nor private business had an opportunity to contribute to market reforms in housing and communal services until now. The prognosis of population participation increase in the management of the housing fund was not reliable as the payments for housing and communal services increased.

The process of decision-making by homeowners is quite complex objectively. There was the situation when people with absolutely different level of wellbeing live in the same houses. At the same time, the strategy of the least provided strata is to maximize the saving of expenses related to housing, even if this leads to the deterioration of its quality and the decrease of selling price. Such a strategy is the opposite of the strategy of owners from more prosperous strata, which put forward the factors of housing quality and decent living conditions. It is difficult to harmonize such opposite tendencies in practice, which makes it difficult to make management decisions in the interests of the owners of both groups. Nevertheless, the authorities place high hopes on the activation of the population position in the field of quality control and the quantity of consumed housing and communal services. The change of granting benefit and subsidy mechanism should promote this: their listing directly to residents rather than to service providers, as well as the revival of institutions of housekeepers, the elders in an entrance, and so on.

The situation of private business in the sphere of housing and communal services is more complicated [9]. Small businesses that come to the market of housing services as contractors can improve the quality of housing services somewhat. However, due to their small size, the lack of experience in the housing and communal service functioning, such firms can not have a significant impact on institutional changes in the housing sector.

\section{Conclusions}

Due to a stable demand and a low elasticity of housing and communal service consumption the enterprises of the industry are extremely attractive 
for large businesses, which can become a real driving force for market reforms in housing and communal services, which provides institutional changes in this sector of the economy.

\section{Summary}

Based on the results of the work, the group of specific risks, largely inherent in housing and communal services, and significantly affecting the results of financial activities of the managing subjects within the housing and communal services was reviewed and analyzed.

Using the example of the management model of costs to reduce the risks of a managing subject within the sector of housing and communal services, it is shown that with the growth of costs for the carrying out of measures to minimize production and technological risks, the value of the costeffectiveness ratio decreases. The studies specific to the housing and communal sector of risks such as the risk of population non-payment, the risk of budgetary defaults and the risk of bankruptcy disclosed their content and the nature of the impact on financial results of the industry governing subjects. The paper presents practical recommendations to minimize the consequences during the implementation of each group of these risks.

The materials of the article are of practical value for the management of housing and communal enterprises interested in the reduction or complete avoidance of industry specific risks and in financial stability of economic entity increase.

The paper shows that the enterprises of the industry are an attractive sphere for big business due to stable demand and low elasticity of housing and communal service consumption.

A full payment for housing and communal services by population creates financial prerequisites for private investment in housing and communal services. However, in this case, appropriate restrictions are necessary, since the activities of municipal organizations are monopolistic, which can determine the nature of their activities in the management of multi-apartment buildings. In this regard, the development of a closer interaction of business, government and population can balance the interests of all stakeholders in the processes of housing and communal service provision and consuming.

\section{Acknowledgements}

The work is performed according to the Russian Government Program of Competitive Growth of Kazan Federal University.

\section{References}

1. Beck Ulrich. World at Risk; Cambridge: Polity Press, 2009.

2. Dwyer Tom. Accidents at work: A search for a new paradigm in the era of risk society // Manchester University Working Papers, 2003. URL: http://ecsocman.hse.ru/text/17908061.html

3. Hopkin P. Fundamentals of Risk Management. 2nd Edition. Kogan-Page, 2012.

4. Fischbacher-Smith D. and FischbacherSmith M. The changing nature of risk and risk management: the challenge of borders, uncertainty and resilience // Risk Management, 2009. - 11 (1). pp. 1-12.

5. Mironova M.D. Selecting the management strategy by the enterprise of housing and communal services sector under conditions of climatic uncertainty // Actual problems of economy, 2016. - V. 185 ( № 11).- pp. 187-193.

6. Kapustina N.V. Theoretical and methodological approaches to risk management: Monograph. - Moscow: SIC INFRA-M, 2016

7. Sokolov D.V., Barchukov A.V. The basic system of economy real sector organization risk management: Monograph - M.: SIC INFRA-M, 2016.

8. Carraway Andrew. Due diligence as a Way of Life // LowersRiskGroup, 25.02.2014. URL: http://www.lowersriskgroup.com/

9. Mironova M.D. Analysis, essence and principles of risk management as the methodological basis for innovative development of an enterprise management system in the field of housing and communal services // Bulletin of KazGASU, 2011.- No. 2.- pp. 290-294.

10. Kameneva E.A., Mironova M.D. Organizational and financial risks of managing subjects in housing and communal services: content and the ways of minimization // Finance and credit, 2013.- № 46 (574). - pp. 19-26.

11. Kameneva E.A., Shokhin E.I. Financial mechanism of energy efficiency increase and financial stability of managing organizations for housing and communal services of Russia // Finances and credit, 2013.- № 26 (554) - pp. 9-14.

12. Ulrikh M.A. Energy service contracts in the housing fund: new opportunities for management companies // Housing and communal services: Journal for a head and a chief accountant, 2010.- No. 10 - pp. 15-20. 